\title{
Exploring the "Weekend Effect" on the Care of Patients with Left Ventricular Assist Devices
}

Citation: Ogunbayo G (2018) "Exploring the "Weekend Effect" on the Care of Patients with Left Ventricular Assist Devices"

The VAD Journal, 4. doi: https://doi.org/10.13023/vad.2018 .06

Editor-in-Chief: Maya Guglin, University of Kentucky

Received: May 19, 2018

Accepted: July 1, 2018

Published: July 2, 2018

(c) 2018 The Author(s). This is an open access article published under the terms of the Creative Commons Attribution-

NonCommercial 4.0 International License

(https://creativecommons.org/lice nses/by-nc/4.0/), which permits unrestricted non-commercial use, distribution, and reproduction in any medium, provided that the original author(s) and the publication source are credited.

Funding: Financial support: Penny Warren Research Award

Competing interests: Not applicable

\section{Gbolahan Ogunbayo*1, Le Dung Ha ${ }^{2}$, Naoki Misumida ${ }^{1}$, Ayman Elbadawi ${ }^{2}$, Qamar Ahmad ${ }^{2}$, Remi Okwechime ${ }^{3}$, Deborah Akanya ${ }^{4}$, Andrew Kolodziej ${ }^{1}$, Claude S Elayi ${ }^{1}$, and Maya Guglin ${ }^{1}$}

*Corresponding author: gogunbayo@uky.edu

${ }^{1}$ University of Kentucky, Lexington, KY

${ }^{2}$ Rochester General Hospital, Rochester, NY

${ }^{3}$ Wyckoff Heights Medical Center, New York, NY

${ }^{4}$ St Vincent's Medical Center, Bridgeport, CT

\section{Background}

Many studies have described differences in in-hospital outcomes and length of stay between patients treated for major cardiac conditions on weekdays versus weekends. ${ }^{1}$ Our study aimed to explore the "weekend effect" on in-hospital care among patients with left ventricular assist devices.

\section{Methods}

Using data from the National Inpatient Sample (NIS) database, with a weighted estimate of more than 35 million admissions per year. ${ }^{2}$ We identified patients 18 years or older with an ICD code signifying presence of a LVAD. Characteristics, comorbidities and clinical outcomes were compared between patients admitted on 
a weekend versus patients admitted on a weekday. The outcomes of interest were in-hospital all-cause mortality and length of hospital stay (LOS).

\section{Results}

Patients admitted on weekend days were younger, otherwise both groups were similar with respect to comorbidities. Patients admitted on weekend days were more likely to have cardiogenic shock, septic shock and respiratory failure. They were also more likely to require mechanical ventilation and undergo cardiac transplantation. Patients admitted on a weekend day however had a shorter hospital median hospital stay. This remained significant after multivariate analysis (OR .81 95\% Cl .72-.91, p<0.01).

Our data analysis from this large database demonstrates no effect of weekend admission on all-cause mortality among patients with LVADs, although patients admitted on weekend days were more likely to have shorter hospital stay.

Keywords: LVAD, weekend effect, complications

\section{Introduction}

Many studies have described differences in in-hospital outcomes and length of stay between patients treated for major cardiac conditions on weekdays versus weekends. ${ }^{1}$ Our study aimed to explore the "weekend effect" on in-hospital care among patients with left ventricular assist devices. Our hypothesis was that given the specialized and urgent care needed in the care of these patients that outcomes will be worse among LVAD patients admitted on Weekend days.

\section{Methods}

Our analysis was done using data from the National Inpatient Sample (NIS) database, with a weighted estimate of more than 35 million admissions per year. ${ }^{2}$ We identified patients 18 years or older with an ICD code signifying presence of a LVAD (V43.21). Using weighted data, we identified patients admitted on a weekday and weekend, from 2010 to 2014. Admission characteristics, comorbidities and clinical outcomes were compared between patients admitted on a weekend versus patients admitted on a weekday. The outcomes of interest were in-hospital all-cause mortality and length of hospital stay (LOS). Logistic regression analysis of weekend admissions was performed using all variables that were statistically significant in multivariate analysis, with mortality as the primary outcome.

\section{Results}

Data on about 31,850 patients were analyzed. The most common diagnoses were device complication (13.3\%), congestive heart failure (12.3\%) and gastrointestinal hemorrhage (12.2\%). The mean age was $58.4 \pm 13.4$ years, $23.8 \%$ were female and $17.6 \%(n=5,595)$ patients were admitted on a weekend day. Patients admitted on weekend days were younger, although by 0.5 years. This difference although statistically significant, we doubt that there is no clinical significance of this difference. Otherwise both groups were similar with respect to comorbidities 
(Table 1a). Patients admitted on weekend days were more likely to have cardiogenic shock, septic shock and respiratory failure. They were also more likely to require mechanical ventilation and undergo cardiac transplantation (Table 1b). Patients admitted on a weekend day however had a shorter hospital median hospital stay. This remained significant after multivariate analysis (OR .81 95\% Cl $.72-.91, \mathrm{p}<.01)$. Mortality was higher among patients admitted on weekend days.

This was however not significant after multivariate analysis (OR 1.07, 95\% Cl .72$1.61 ; p=.74)$.

Table 1: Admission/baseline characteristics and outcomes

\begin{tabular}{|c|c|c|c|}
\hline A Characteristics & $\begin{array}{l}\text { Weekend } \\
\text { Admission } \\
\mathrm{N}=5,592(\%)\end{array}$ & $\begin{array}{l}\text { Weekday } \\
\text { Admission } n= \\
26255(\%)\end{array}$ & $\begin{array}{l}\mathrm{P} \\
\text { Value }\end{array}$ \\
\hline Age & $58.0 \pm 13.6$ & $58.5 \pm 13.3$ & 0.01 \\
\hline Indicator of sex & $1336(23.9)$ & $6248(23.8)$ & 0.96 \\
\hline Race: Caucasian Vs. Others & $3161(62.7)$ & $15375(64.3)$ & 0.35 \\
\hline Hypertension & 3257 (58.2) & $15412(58.7)$ & 0.75 \\
\hline Diabetes Mellitus & $2172(38.8)$ & 10976 (41.8) & 0.05 \\
\hline Chronic Kidney Disease & $1972(35.2)$ & $9964(38)$ & 0.07 \\
\hline Obesity & $722(12.9)$ & $3898(14.8)$ & 0.14 \\
\hline Anemia & 1706 (30.5) & $8171(31.1)$ & 0.64 \\
\hline Coronary Artery Disease & 3205 (57.3) & $14719(56.1)$ & 0.43 \\
\hline Primary diagnosis: Device Complication & $670(12)$ & 3571 (13.6) & 0.14 \\
\hline Primary diagnosis: $\mathrm{CHF}$ exacerbation & $679(12.1)$ & 3223 (12.3) & 0.89 \\
\hline $\begin{array}{l}\text { Primary diagnosis: Gastrointestinal } \\
\text { Hemorrhage }\end{array}$ & $692(12.4)$ & $3182(12.1)$ & 0.82 \\
\hline Teaching Hospital & $25,578(97.4)$ & $5254(97.4)$ & 0.94 \\
\hline Rural Hospital & $52(0.2)$ & $19(0.3)$ & 0.21 \\
\hline $\begin{array}{l}\text { Elevated severity of IIIness (Major or } \\
\text { extreme loss of function) }\end{array}$ & $5139(91.8)$ & $23660(90.1)$ & 0.08 \\
\hline \multicolumn{4}{|l|}{ B Outcomes } \\
\hline Cardiac arrest & $167(3)$ & $699(2.7)$ & 0.53 \\
\hline Cardiogenic shock & $446(8)$ & $1296(4.9)$ & $<0.01$ \\
\hline Septic shock & $173(3.1)$ & $494(1.9)$ & 0.01 \\
\hline TIA/Stroke & $422(7.5)$ & $1664(6.3)$ & 0.16 \\
\hline Respiratory failure & $837(15)$ & $2801(10.7)$ & $<0.01$ \\
\hline Acute renal failure & $1359(24.3)$ & 5910 (22.5) & 0.19 \\
\hline Hemorrhage & $30(0.5)$ & $313(1.2)$ & 0.04 \\
\hline Balloon counterpulsation & $34(0.6)$ & $208(0.8)$ & 0.50 \\
\hline Intubation/Mechanical ventilation & $658(11.8)$ & $2364(9)$ & $<0.01$ \\
\hline Blood transfusion & $1598(28.6)$ & $7398(28.2)$ & 0.81 \\
\hline Cardiac transplant & $387(6.9)$ & $1140(4.3)$ & $<0.01$ \\
\hline Mortality & $346(6.2)$ & $1209(4.6)$ & 0.03 \\
\hline LOS (Days) & $5(8)$ & $6(9)$ & $<0.01$ \\
\hline
\end{tabular}




\section{Discussion}

Our analysis of the large database showed no difference in in-hospital all-cause mortality and a shorter hospital stay for LVAD patients admitted on weekend days when compared to weekdays, after controlling for possible confounders. The findings in this study are similar to those found in studies by Kistis et al. ${ }^{3}$ and more recently by Kumar et al. ${ }^{4}$ showing no significant difference in the care of patients with cardiac conditions after controlling for possible confounders. A recent metaanalysis suggested that the weekend effect remains highly heterogeneous and limited. ${ }^{1}$ Ricciardi et al. suggested that low staffing and admission to hospitals with more residents trainees impacted weekend mortality albeit modestly at best. $^{5}$

Patients with LVADs need special care, hence may only be treated at tertiary or quaternary centers with readily available specialized care and this may have a part to play in our finding. In fact, $97.4 \%$ of LVAD patients in this study initially presented for care at a teaching hospital compared to $0.2 \%$ who presented to a rural hospital. Findings in the study could however not explain the shorter hospital stay among patients admitted on weekend days. One possibility is that some patients were admitted because of unavailable outpatient services on weekend days, not because of the severity of their illness. For example, more patients presented on the weekend for abnormality of their coagulation profile $(2.6 \% \mathrm{vs}$ $0.5 \%, p<.01)$. Despite this finding, this explanation remains purely speculative.

Some of the limitations of our study encompass those that are generally associated with the retrospective studies including possibility of selection, information and misclassification bias. Although multivariate analysis was performed, the possibility of confounders still exists. Given the nature of the variables available, comparison of a marker of severity of disease between both groups using well known and validated scores (i.e. APACHE or SOFA) could not be done. Also, we could not tell from the data whoch LVAD was placed as destination therapy of bridge to transplant. Lastly, the NIS database only provides inpatient all-cause mortality and no long term survival data.

Our data analysis from this large database demonstrates no effect of weekend admission on all-cause mortality among patients with LVADs, although patients admitted on weekend days were more likely to have shorter hospital stay. The model of care of these patients is worth studying to identify practices that have led to these findings.

\section{References}

1. Hoshijima H, Takeuchi R, Mihara T, Kuratani N, Mizuta K, Wajima Zl, Masaki E, Shiga T. Weekend versus weekday admission and short-term mortality: A meta-analysis of 88 cohort studies including 56,934,649 participants. Medicine. 2017 Apr;96(17).

2. Agency for Healthcare Research and Quality, Rockville M. HCUP NIS Description of Data Elements. Healthcare Cost and Utilization Project (HCUP). www.hcup-us.ahrq.gov/db/vars/hosp_bedsize/nisnote.jsp. Published 2008. Accessed November 25, 2016. 
3. Kostis WJ, Demissie K, Marcella SW, Shao Y-H, Wilson AC, Moreyra AE. Weekend versus Weekday Admission and Mortality from Myocardial Infarction. N Engl J Med. 2007;356(11):1099-1109.

4. Kumar G, Deshmukh A, Sakhuja A, Taneja A, Kumar N, Jacobs E, Nanchal $R$, Milwaukee Initiative in Critical Care Outcomes Research (MICCOR) Group of Investigators. Acute Myocardial Infarction. JACC. 2015 Jan 20;65(2):217-8.

5. Ricciardi R, Nelson J, Roberts PL, Marcello PW, Read TE, Schoetz DJ. Is the presence of medical trainees associated with increased mortality with weekend admission? BMC Med Educ. 2014;14(1):4. 